\title{
«Pata es la traviesa»: la cortesana Estefanía, el engaño mutuo y la sífilis en El casamiento engañoso
}

\author{
Adrián J. SÁEZ*
}

En El casamiento engañoso, el alférez Campuzano relata a su amigo el licenciado Peralta la historia de sus amores y desgracias con una dama que dice llamarse doña Estefanía de Caicedo. Tras el oportuno galanteo se unen en un matrimonio que comienza felizmente. Sin embargo, tanto uno como otro han tratado de salir ventajosos de su enlace, al que han accedido con aviesas intenciones: él desea apoderarse de la fortuna que ella aparenta, mientras ella pretende hacerse con las supuestas riquezas del alférez. Cuando se descubre la falsedad de las posesiones de Estefanía, ella huye con las quiméricas joyas de Campuzano y este queda igualmente burlado, sin beneficios y enfermo. Sus respectivas ambiciones y cuidadas estrategias quedan frustradas. Por ello, el licenciado Peralta puede decir: «Desa manera $[\ldots]$ entre vuestra merced y la señora Estefanía pata es la traviesa», a lo que responde el alférez: « $¡ Y$ tan pata [...] que podemos volver a barajar!» (p. 641) .

La novela comienza con la aparición en escena del convaleciente Campuzano, referida por un narrador innominado:

Salía del Hospital de la Resurrección, que está en Valladolid fuera de la puerta del Campo, un soldado que, por servirle su espada de báculo y por la flaqueza de sus piernas y amarillez de su rostro, mostraba bien claro que, aunque no era el tiempo muy caluroso, debía de haber sudado en veinte días todo el humor que quizá granjeó en una hora (p. 629).

* GRISO-Universidad de Navarra.

1 Cito siempre por la excelente edición de García López; en ocasiones modifico la puntuación sin indicarlo. 
El desdichado presenta algunos síntomas del «mal francés» que comenta Girolamo Fracastoro en De contagione et contagiosis morbis (1546), tales como el cansancio y el dolor corporal («una certa stanchezza del corpo», «fatica», «grandi dolori ai muscoli»), la palidez o amarillez de la cara («un pallore nella faccia») y ha tolerado intensos sudores fruto de uno de los sistemas de curación existentes ${ }^{2}$. En efecto, al reencontrarse con Peralta, quien se sorprende de hallar a su amigo en Valladolid y en tan penosa condición, el alférez confiesa otro síntoma de la enfermedad sufrida, las reacciones cutáneas («pustole crostose», «pustole ulcerate»): «salgo de aquel hospital de sudar catorce cargas de bubas que me echó a cuestas una mujer que escogí por mía, que non debiera» (pp. 629-630). Además, si se confía en Amezúa y Mayo $^{3}$, el citado hospital de Valladolid era destino acostumbrado de los «bubosos» en Valladolid, sito muy cerca de la casa habitada por el propio Cervantes durante su estancia en la ciudad. Precisamente allí acaba Campuzano al presentar más señales de la dolencia, como él mismo cuenta:

Mudé posada y mudé el pelo dentro de pocos días, porque comenzaron a pelárseme las cejas y las pestañas, y poco a poco me dejaron los cabellos y antes de edad me hice calvo, dándome una enfermedad que llaman lupicia y por otro nombre más claro la pelarela. Halleme verdaderamente hecho pelón, porque ni tenía barbas que peinar, ni dineros que gastar. Fue la enfermedad caminando al paso de mi necesidad, y como la pobreza atropella a la honra y a unos lleva a la horca y a otros al hospital y a otros les hace entrar por las puertas de sus enemigos con ruegos y sumisiones, que es una de las mayores miserias que puede suceder a un desdichado, por no gastar en curarme los vestidos, que me habían de cubrir y honrar en salud, llegado el tiempo en que se dan los sudores en el Hospital de la Resurrección me entré en él, donde he tomado cuarenta sudores (pp. 642-643).

2 Fracastoro, 1950, p. 60. Este médico bautiza la enfermedad con el nombre más habitual, sífilis, en su poema en hexámetros Syphilis sive morbus Gallicus (1530). Según explica Amezúa y Mayo, 1962, pp. 412-416, una cura consistía en hacer sudar copiosamente al enfermo, para lo cual se le abrigaba fuertemente en una habitación pequeña, cerrada y calentada con braseros, mantas y esteras, amén de imponerle un régimen muy severo que incluía cocimiento de guayacán (o palo de Indias), recomendarle el sueño y la quietud, todo ello durante unos treinta días como término habitual, especialmente entre la primavera y el otoño. Este método, lógicamente, dejaba a los sujetos en un estado de extrema debilidad como muestra Campuzano, quien también ha comido «muchas pasas y almendras» (p. 646), que avivan la memoria. Muy en boga estuvieron los tratamientos con mercurio, siguiendo la tradición árabe de emplearlo en unciones pese a su alto nivel tóxico; escribe Perry, 1993, p. 261: «parecían tener efectos más inmediatos, pero también se les acusaba de causar muertes. Como dijo un médico de la época, las curas de mercurio eran más dañinas que la enfermedad». En La lozana andaluza (Mamotreto XXIII) se cita un ungüento calmante conocido como "populeón», compuesto de manteca de cerdo, hojas de adormidera y yemas de álamo negro.

3 Amezúa y Mayo, 1962, pp. 413-414. 


\section{LOS ARDIDES DE ESTEFANÍA, UNA AUTÉNTICA «DAMA SERVIDA»}

En el relato retrospectivo de su «casamiento» o «cansamiento», Campuzano culpa a Estefanía de tal regalo de despedida, consecuente con la fama de su burladora, a quien conoce «derribado el manto hasta la barba sin dejar ver el rostro más de aquello que concedía la raridad del manto. Y aunque le supliqué que por cortesía me hiciese merced de descubrirse, no fue posible acabarlo con ella, cosa que me encendió más el deseo de verla» (p. 631). Nótese que entran en contacto en una posada, local frecuentado por mujeres de mala consideración. Allí, Estefanía únicamente permite que Campuzano vislumbre sus encantos, pero no los descubre: «Y para acrecentarle [el deseo de verla] más - o ya fuese de industria o acaso - sacó la señora una muy blanca mano con muy buenas sortijas» (p. 631). Así pues, actúa como una «tapada» que aviva con su calculada actitud el apetito del soldado. Esta costumbre social se juzgó peligrosa ya en la época y se prohibió en varias disposiciones porque, a la vez que puede considerarse un medio de lograr un margen de libertad mayor ${ }^{4}$ y un arma de seducción, era una forma de ejercer la prostitución denunciada en las pragmáticas desde $1586^{5}$. Según escribe Brunel en su Voyage d'Espagne (1655) a propósito de las prostitutas, «Van con velos negros, y los repliegan sobre el rostro, no dejando sino un ojo al descubierto» ${ }^{6}$. Amén de ser un útil ardid para atraer pretendientes, eliminaba o reducía las fronteras sociales; tal como apunta Cruz de Amenábar, «las prostitutas y cortesanas, que fueron las primeras en usarlo [el manto] con intenciones galantes, podían darse fácilmente bajo el tapado la apariencia de "damas de calidad" ${ }^{7}$. No en vano, en distintas disposiciones desde el reinado de Alfonso XI se regulaba el vestido de las meretrices. En el Siglo de Oro el atuendo tenía un valor identificador y diferenciador en la sociedad, que mediante el disfraz también

4 Gentil da Silva, 1990, afirma que sólo existían dos vías de liberación para la mujer, la prostitución y el matrimonio. Sobre la libertad de la prostituta ver Profeti, 1994, p. 199; Cantizano Pérez, 2010, pp. 164-165.

5 Recuérdese el entremés de El vizcaíno fingido, donde Brígida y Cristina comentan las sanciones contra el uso abusivo de las «tapadas». Anota Cruz de Amenábar, 2000, p. 117: «El manto fue una herencia de la España mora, donde su uso — directamente ligado al velamiento del rostro y el cuerpo- corría parejo con la condición de reclusa impuesto a la mujer por esa cultura. Desde el siglo XVI, sin embargo, el manto se transformó en España y posteriormente en América en un instrumento de seducción y coquetería. El velo, que apenas permitía adivinar la cara, o que dejaba sólo un ojo a la vista, añadía picardía al atractivo de una bonita mirada» (la cursiva es mía). Ver también Deleito y Piñuela, 1966, pp. 63-70 y pp. 287-289 para las prohibiciones. Recuérdese que en el famoso proceso Ezpeleta en el que se vio envuelto Cervantes intervino una tapada llamada Inés Hernández; ver sólo Canavaggio, 1997; Hsu, 2005, pp. 320-321, n. 1 y 5.

6 Citado en Deleito y Piñuela, 1967, p. 38. Para las meretrices ver sólo Profeti, 1994 y Temprano, 1995, pp. 73-90.

7 Cruz de Amenábar, 2000, p. 117. Y al revés, algunas mujeres que no eran «del oficio» se tapaban con pretexto de honestidad (Alonso Hernández, 1977, p. 726), como se ve en una academia en El diablo Cojuelo, IX, p. 165. 
podía emplearse para ocultar la identidad personal y social. Según Peris ${ }^{8}$, el Consell de Valencia prohibió a las mujeres públicas el uso de prendas propias de las damas, llegando a detenerse a quien no llevase ropas adecuadas a su condición. Antonio León Pinelo ofrece el siguiente testimonio en Velos antiguos y modernos en los rostros de las mujeres (1641):

el tapárselos [los rostros] es malo, porque naturalmente es lascivo, con capa o velo de la honestidad; es gala de las que quieren parecer damas, cebo de los hombres, señuelo de la juventud, tercero de la comunicación, engaño de la hermosura, lenocinio de la pudicia y adulación de la fealdad, cautela de los defectos, ocasión de la desenvoltura y espía doble que avisa al enemigo para que acometa la fuerza que se defiende. [...] Apetecido de las mujeres porque les hace parecer lo que no son: juzgándose por hermosa tapada, la que descubierta se conociera por abominable; porque ocultándole lo defectuoso del rostro, sólo manifiesta lo que las más tienen mejor que son los ojos, y aún de estos el uno, por si falta el otro, y con esto incitan, llaman y atraen (vol. 2, p. 332).

Si se explora el siempre revelador léxico, se encuentra que en lengua de germanía, «mujer de manto tendido» es la ramera que no trabajaba en un prostíbulo y que incluso podía tener otras ocupaciones ${ }^{9}$, al igual que parece serlo Estefanía.

Tal como anotaba Pinelo, es a la par un embozo que oculta el rostro para que, aún viejo y feo, pueda parecer hermoso y apetecible, lo cual parodia Quevedo en el romance «Confisión que hacen los mantos de sus culpas, en la premática de no taparse las mujeres» (Un Heráclito cristiano..., núm. 249). Así, Estefanía se descubre al tiempo y Campuzano contempla la realidad frente a sus expectativas: ella era «una mujer de hasta treinta años, a quien conocía por las manos. No era hermosa en estremo, pero éralo de suerte que podía enamorar comunicada» (p. 632), esto es, más por su conversación y trato que no por su belleza física, desplegando un abanico de encantos propios del arte seductor de una cortesana, ya hacia el fin de la primavera de su belleza ${ }^{10}$. Además, como meretriz y buscona confiesa: «simplicidad

8 Peris, 1990, p. 184. Ver los comentarios de Torres en su reciente edición de La pícara Justina, pp. 29-32.

9 Alonso Hernández, 1977, p. 511; 1979, p. 41. Estas mujeres de vida licenciosa eran también nombradas «encubiertas», «descubiertas», «acechonas», «búhos», «tapadas de medio ojo», «lechuzas de medio ojo», «mujeres de medio ojo» o «putas de manta», como se ve en La lozana andaluza, XX, p. 102: «cuántas putas hay, con manta o sin manta». Asimismo, la «recoleta» y la «pecadora del paño» pertenecen al conjunto de las tapadas (p. 40); menos comunes eran las «ocultas» (p. 42). Cortés de Tolosa en el Lazarillo de Manzanares se refiere a ellas como «aquellas mujeres que aunque compran el manto entero no se sirven más que del medio» (I, p. 92); también dice «que se tapan de puntería» (VI, p. 132).

10 Una galería de estas prácticas puede verse en la Asinaria de Plauto; ver también Hsu, 2005, pp. 311-313. A propósito del habla como arma de seducción dice Suárez de Figueroa en el discurso «De las rameras y de sus secuaces en parte», en Plaza universal de todas ciencias y artes, II, p. 71: «Lo más donoso es ver con cuánta facilidad imitan el trato y lenguaje señoril, con cuánta entonación hablan». 
sería si yo quisiera venderme a vuesa merced por santa. Pecadora he sido y aún ahora lo soy, pero no de manera que los vecinos me murmuren, ni los apartados me noten» (p. 633). Esta proposición de matrimonio a Campuzano, tan aparente y retóricamente sincera es uno de los principales argumentos esgrimidos por algunos críticos para valorar positivamente a Estefanía. Pregona su discreción, que asegura una honestidad aparente o ambigua, al igual que su negativa a acceder a las solicitudes del alférez en el primer encuentro, instándole a encontrarse en privado, a diferencia de otras mujeres públicas como las cantoneras. Ahora bien, su cuidado parlamento muestra a las claras su condición pecaminosa, que no es notoria porque se sirve de la disimulación y el recato. Con sus palabras intenta aparentar honestidad con miras a obtener buenos beneficios. Donde un sector de la crítica ve una sinceridad conmovedora fruto del arrepentimiento es, si se contempla dentro de la estructura global de la obra, una muestra de hipocresía suprema. En acertada expresión de Egido ${ }^{11}$, «el engaño empieza por el discurso mismo, ya que es el uso perverso de la elocución el que aparece, en primera instancia, por boca de quien iba a ser causa de dicho engaño»; estas «palabras aparentemente buenas, dichas con habla suave», indica que se trata de «un caso claro de seducción, en el más puro sentido etimológico de conducir al mal bajo pretensiones de bondad». Esto se aprecia también en el uso que hace del léxico mercantil y que remite a la prostitución, como ha estudiado Hutchinson $^{12}$ : ella «se vende», descubre sus taras y pondera sus virtudes, declara sus posesiones, ofrece sus servicios, etc. El deseo y la falta de juicio de Campuzano le impiden apreciar la verdad y sucumbe ante tal despliegue de encantos y ardides.

Con todo, el estatuto liviano del personaje ha sido cuestionado por un cierto sector de la crítica, que duda de su condición de cortesana. Las otras evidencias aportadas son su tardío robo y posterior fuga, tras seis días alejada de su supuesta morada (tantos como las jornadas de feliz farsa). Márquez Villanueva $^{13}$ subraya que no se lleva los costosos vestidos de Campuzano, «lo único que el baúl contenía de algún valor», pero el tesoro del alférez se revela como falso a posteriori, solamente cuando éste lo confiesa y Estefanía ya se lo ha llevado, de modo que la estafadora no podía tener noticia alguna de ello. No cuenta si la intención inicial era el expolio, sino que cuando la

11 Egido, 2011, p. 41.

12 Hutchinson, 2001, pp. 171-177. No creo que este parlamento pueda expresar que, pese a un vivir equívoco, «no deja de ser una mujer discreta y digna de respeto» (Hsu, 2005, p. 315).

13 Márquez Villanueva, 2005, p. 276; no obstante, reconoce lo siguiente: «Confiesa ésta [Estefanía] tener a sus espaldas una vida galante conforme al modelo de alta prostitución que decían de "dama servida", una realidad social de grupo bien conocida por Cervantes, en cuya inmediata familia estuvo bien representada» (p. 272). Ver las objeciones de El Saffar, 1976, pp. 28 y 30-33; Rodríguez-Luis, 1989, 2, p. 49; Hsu, 2005, pp. 314-316; Márquez Villanueva, 2005, pp. 271-273 y p. 373, n. 8; Darnis, 2007. Zafra, 2009, pp. 87-114, en su estudio sobre la prostitución en algunas obras cervantinas, no se acerca a esta figura (sólo es nombrada: p. 165); Arredondo, 1993, p. 18, inserta a Estefanía entre las cortesanas que descienden de las pícaras de mala vida; y Delicado Puerto, 2011, pp. 93-94 la estudia como una reescritura de la Magdalena, modelo de pecadora penitente. 
maraña se descubre ella decide fugarse robando a su legítimo marido ${ }^{14}$. Se alega que desea realmente casarse con Campuzano para redimirse de una vida pecaminosa «buscando marido honrado, aunque sea por medio de cualquier embuste» (p. 638), en pos de una seguridad familiar seguramente desconocida para ella ${ }^{15}$; pero, si es así, ¿por qué renuncia ante las dificultades que le salen al paso? Sus teóricos deseos son, en verdad, muy débiles o inexistentes, porque realmente tiene un amante con el que acaba huyendo.

Es cierto que, por otro lado, durante seis días Campuzano gozó «del pan de la boda» (p. 635) gracias a las agradables atenciones de Estefanía. De hecho, él confiesa: «por verme tan regalado y tan bien servido, iba mudando en buena la mala intención con que aquel negocio había comenzado» (p. 636). Parece que comienza a desistir de las ocultas ambiciones con que se había acercado a la dama. Esta lograba así que el alférez olvidase sus objetivos (aunque ella no los conociese) o que se descuidase y estuviese así más fácilmente a su merced. Porque, al final, Campuzano es engañado y pierde gran parte de sus «valiosas» pertenencias. En suma, parece probarse que «Una cortesana es cariñosa cuando ve un botín al alcance de la mano», según se lee en Los Menecmos de Plauto (acto I, escena 3, v. 195) ${ }^{16}$. Una vez conocido el desenlace de la historia, parece legítimo creer que todos los cuidados de Estefanía estaban orientados a engañar a su víctima, quien así recibía el justo castigo a sus respectivos fines. La diferencia radica en que el alférez muestra un asomo de cambio, lo cual no resta para que su culpabilidad en el engaño mutuo sea notable; mientras, Estefanía reacciona fugándose con su amante. Campuzano, en fin, no ha sido capaz de diferenciar entre apariencia y realidad; pero tampoco Estefanía ha atinado con la verdad. El casamiento es una representación al que los dos han accedido con segundas intenciones y gracias al que disfrutan de una breve vida ilusoria, pero nada más ${ }^{17}$. El engaño trazado por la cortesana dentro de la ficción cervantina se desvanece con la llegada de la verdadera dueña de la casa. Entonces, Estefanía dice a Campuzano que su amiga quiere burlar al hombre que la acompaña; la traza consistía en «darle a entender que aquella casa y cuanto estaba en ella era todo suyo, de lo cual pensaba hacerle carta de dote, y que, hecho el casamiento, se le daba poco que se descubriese el engaño» (pp. 637-638). Tras este parlamento se adivina el auténtico proyecto de Estefanía, la forma en que ha cautivado al alférez. Las palabras de doña Clementa Bueso, la amiga que había prestado su casa a Estefanía, no pueden ser más explícitas: «la mentira es todo cuanto os ha dicho doña Estefanía, que ni ella tiene casa, ni hacienda, ni otro vestido del que trae puesto» (p. 639).

14 Para Lloris, 1970, pp. 16-17, el robo es la menos deseable de las opciones, pero, añado, es la que finalmente triunfa.

15 Así por ejemplo en Hsu, 2005, pp. 315-317.

16 Escribe a propósito Deleito y Piñuela, 1967, p. 41: «Aunque la inclinación de las meretrices no era, naturalmente, sino la rapiña y la explotación, fingían ridículos transportes de pasión y celos».

17 Ver ahora Costa Vieira, 2010. 
«Casamiento vale tanto como caso y miento» (Covarrubias) es un repetido juego de palabras por disociación que viene como anillo al dedo para este relato. Pese a las similitudes, muy diferente es el episodio del Quijote (II, 22) en el que Basilio logra casarse con Quiteria mediante un ingenioso ardid; entonces, don Quijote concluye que «no se pueden ni deben llamar engaños los que ponen la mira en virtuosos fines», motivación inexistente en esta mendaz unión. Con toda razón Forcione ${ }^{18}$ puede calificar este casamiento como una perversión del sacramento del matrimonio, pues la hipocresía de ambos contrayentes preside su tálamo. Por definición, en un contrato libre entre dos partes no ha lugar para el engaño, por lo que la petición de nulidad estaría justificada. Sin embargo, Campuzano no muestra intenciones de querer romper un vínculo establecido como indisoluble: Estefanía sigue siendo «su prenda», aunque no tiene obligación de buscarla y es mejor agradecer que se haya ido para evitar una recaída, tal como le reconforta Peralta. El matrimonio motivado por la ambición y el engaño recíproco ya existía en la tradición literaria anterior y en la narrativa picaresca (de protagonista masculino o femenino), que presenta distintos casos de estafas. Esta original aportación de Cervantes a un esquema ya establecido contiene una lección ejemplar, que no podía faltar: si en otras obras reivindica la libertad y la igualdad entre los contrayentes, mediante el ejemplo ex contrario de proceder que representa El casamiento engañoso reflexiona sobre la sinceridad y las motivaciones del matrimonio.

Creo que la comparación de Estefanía con la descripción de Elena en $L a$ hija de Celestina de Salas Barbadillo puede ser significativa por la cercanía de ambas figuras: ella es prostituta reconocida desde los catorce años (III, p. 112) y «una vil ramera que había sido y era pasto común, entregándose por bajos precios a todos aquellos que con medianas diligencias la pretendían» (IV, p. 116). Aparece al comienzo «tapada de medio ojo» (I, p. 86) y asimismo se esfuerza por mostrar otros encantos de los que se aprovecha Estefanía: «limpiándose ya con un lienzo los ojos por mostrar la blanca mano» (II, p. 99). En El mundo por de dentro, Quevedo sintetiza en clave satírico-paródica el modus operandi de una tapada, pasaje en el que se aprecian varias argucias también empleadas por Estefanía:

Venía una mujer hermosa, trayéndose de paso los ojos que la miraban y dejando los corazones llenos de deseos. Iba ella con artificioso descuido escondiendo el rostro a los que ya le habían visto y descubriéndole a los que estaban divertidos. Tal vez se mostraba por velo, tal vez por tejadillo; ya daba un relámpago de cara con un bamboleo de manto, ya se hacía brújula mostrando un ojo solo, ya tapada de medio lado descubría un tarazón de mejilla. Los cabellos, martirizados, hacían sortijas a las sienes. El rostro era nieve y grana y rosas que se conservaban en amistad esparcidas por labios, cuello y mejillas; los dientes transparentes; y las manos, que de rato en rato nevaban el manto, abrasaban los corazones. El talle y paso ocasionando

18 Forcione, 1984, p. 137. 
pensamientos lascivos; tan rica y galana como cargada de joyas recibidas y no compradas (en Los sueños, pp. 299-301).

Todo lo anteriormente señalado ya apunta a su condición de cortesana. La sospecha crece porque el único testigo en el enlace por parte de Estefanía fue «un mancebo que ella dijo ser primo suyo» (p. 635), designación entonces usual para el verdadero galán de la mujer ${ }^{19}$. La relación se confirma al fugarse con quien «de luengos tiempos atrás era su amigo a todo ruedo» (p. 642). Esta confesión es muy importante porque desvela que dicha huida tiene todos los visos de haber sido premeditada. Puede decirse que escapa al saber la cólera que posee a Campuzano tras conocer la verdad según le informa su amiga Clementa (aunque primero le tienta desesperarse, 'suicidarse'), pero su amante ya existía antes de conocer su reacción y hasta del casamiento, de modo que tal opción no parece aceptable. Mientras narra lo ocurrido, Campuzano hace notar que durante sus visitas nunca encontraba en la casa «visiones de parientes fingidos»o «amigos verdaderos» (p. 633), cuya existencia descubre a la par que la red en que fue cazado. También en La hija de Celestina se presenta una relación similar, pues Elena oculta su relación con Montúfar, su amante y rufián a la par, bajo nombre de parentesco: «siempre a las horas del acostar hacían compañía, con el seguro de la hermandad en cuya opinión vivían ellos» (VII, p. 143). A la luz de este enlace parece más claro que el matrimonio con Campuzano era un mero intento de buscar ganancias. Por último, la anteposición del tratamiento de «doña» es también una forma de aparentar honra y posición social propio de las cortesanas. Parece probado, pues, que Estefanía es integrante de la cofradía de las mujeres de mala vida, estado idóneo para transmitir la sífilis a Campuzano.

\section{LA ESTAFADORA, EL «MAL FRANCÉS» Y LOS AFEITES}

Los diversos autores que escribieron sobre los orígenes de la misteriosa enfermedad vacilaban en considerarla importada por los conquistadores de los nuevos territorios en las Indias, castigo divino por algún pecado o procedente del envenenamiento del vino o los alimentos, pero posteriormente se concluyó que se transmitía sexualmente por personas de alto riesgo, como las prostitu-

19 La maliciosa alusión es clara en el Guzmán, I, ii, 4: «Una moza o ama que quiere servir de todo, sucia, ladrona, con un hermano, pariente o primo, para quien destaja tantas noches cada semana»; más adelante, de una dama cordobesa se descubre que «el que decía ser su hermano era su galán» (I, II, 8). Recuérdese La tía fingida, novelita atribuida a Cervantes que ya desde el título anuncia la falsía del parentesco, después esclarecido: «se le averiguó [a Claudia] por su misma confesión que la Esperanza no era su sobrina ni parienta, sino una niña a quien había tomado de la puerta de la iglesia» (p. 110); ver Aylward, 1999, para la relación entre esta novela y El casamiento. Sobre estos falsos familiares se lee en El diablo Cojuelo, Tranco III, p. 95: «entraron a otra plazuela al modo de la de los Herradores, donde se alquilaban tías, hermanos, primos y maridos, lacayos y escuderos, para damas de achaque que quieren pasar en la Corte con buen nombre y encarecer su mercancía». 
tas y cortesanas ${ }^{20}$. Ya Covarrubias escribe: «Pegábase principalmente por la comunicación deshonesta». En consecuencia, un modo de frenar su extensión era controlar a las sospechosas de extender la enfermedad, medida que por vez primera recomienda Gaspar Torrilla en su Tractatus cum consiliis contra pudendagram seu morbum gallicum (1497); Rodrigo de Isla en su Tratado contra el mal serpentino (1539) asocia la sífilis con la prostitución incontrolada, y Andrés de León en su Práctica de morbo gallico (1605) recomendaba inspeccionar regularmente a las meretrices ${ }^{21}$. Al principio se abogaba por conservar las mancebías como medio de controlar la sífilis, postura pronto rectificada al considerar tales locales como causa de su propagación debido al incumplimiento de las normativas vigentes y a la falta de control sobre las daifas. Según exponen Jacquart y Tomasset ${ }^{22}$, la nueva epidemia permitía colmar el afán existente de asociar enfermedades y sexualidad, algo ya logrado en la Edad Media al vincular lepra y trato carnal en formas diferentes como la «satiriaris» o el contagio sexual de tal dolencia.

No obstante, Márquez Villanueva ${ }^{23}$ indica que Estefanía «no padecía ella misma la enfermedad, cuyas señales solían ser muy visibles en la imagen literaria de la prostitución. Estefanía era solamente transmisora del morbo y no puede ser dada por responsable de tan grave atentado contra la higiene conyugal». Aduce en su apoyo únicamente el caso concreto de Aldonza, protagonista de La lozana andaluza y la estrella sifilítica que corona su rostro, indicadora del mal: «sobre todo se daba de cabezadas, de modo que le siguió

20 El castigo divino es claro para Francisco López de Villalobos en el Sumario de la medicina en romance trovado, con un tratado sobre las pestiferas bubas (1498), y Francisco Delicado en El modo de adoperare el legno de india occidentale (1529). Las marcas en las zonas genitales apuntan claramente al pecado carnal como su causa. Ver Jacquart y Tomasset, 1989; Perry, 1993; Brioso Santos, 1997; Orozco Acuaviva, 1998; Ponce Cárdenas, 2007.

21 Ver Moreno Mengíbar y Vázquez García, 1997, p. 42. En La lozana andaluza se hace referencia a la cuarentena que se establecía a las prostitutas aquejadas de sífilis para que no pudiesen contagiar la enfermedad a sus clientes: «no os amaléis, que os cerrarán cuarenta días» (Mamotreto XXIV, p. 127); también se relacionan prostitución y muerte por tal enfermedad: «al principio y al medio, cada una le toma como le viene; al último, francés, porque no las deja hasta la muerte» (XXI, p. 108). Comenta García-Verdugo, 1994, pp. 87-88: «Posiblemente Delicado desnariza [sic] a la protagonista para que el lector entienda claramente que de hecho Lozana padece un mal ya entonces asociado a la promiscuidad». Este final se presenta igualmente en La tía fingida, p. 114: «las más de su trato pueblan las camas de los hospitales y mueren en ellos miserables y desventuradas, permitiendo Dios que las que, cuando mozas, se llevaban tras sí los ojos de todos, no haya alguno que ponga los ojos en ellas, etc.». Andando el tiempo, todavía escribió un tratado sobre el particular Prats y Bosch, 1861.Ver el texto de Mariana que incluye Zafra, 2009, p. 29.

22 Jacquart y Tomasset, 1989, p. 193.

23 Márquez Villanueva, 2005, p. 275; ejemplo señalado en p. 374, n. 21. Considera que Campuzano puede estar esbozando «una explicación inocente» (p. 279). La relación entre Cervantes, $L a$ lozana y otras obras de Delicado ya fue estudiada por Vilanova, 1952; Bubnova, 1990, entre otros. Delicado padeció la misma enfermedad que Campuzano, al igual que el Mahúdes histórico (Alonso Cortés, 1942). Bubnova, 1990, p. 578, se pregunta si Cervantes pudo inspirarse en el hecho de que Delicado compuso La lozana durante su estancia en el Hospital de Santiago de los Incurables (alega incluso su malestar para justificarse por haber compuesto el relato: "Cómo se escusa el autor», p. 329) para configurar a Campuzano, quien escribe el Coloquio durante su cura en el Hospital de la Resurrección, pero hay dificultades para tal opción de contacto (ver p. 578, n. 26). 
una gran aljaqueca, que fue causa que le viniese a la frente una estrella» (Mamotreto IV, p. 25) ${ }^{24}$. Esta marca facial vergonzosa, como dice Allaigre, «no es sino el remate del hundimiento de la nariz causado por el mal venéreo» ${ }^{25}$, otro de sus efectos, ridiculizado en el famoso retrato del dómine Cabra en el Buscón.

Es bien cierto que Estefanía no muestra signos apreciables, pero tampoco es condición sine qua non de su oficio ni de padecer el mal sifilítico. Además, en caso de que lo fuese, es lógico que las meretrices tratasen de disimular los estragos físicos causados por la enfermedad, ya con el auxilio de afeites y cosméticos, ya con postizos, etc., jugando con la realidad y las apariencias, con el ser y el parecer, dueto tan caro en el Siglo de Oro. Aquí tampoco se muestra muy hábil Campuzano en discernir lo real de lo fingido. La propia lozana Aldonza cubre con una venda la «estrellica» sifilítica de su frente, razón por la cual se ha considerado la «aljaqueca» un dolor de cabeza real o una excusa para encubrir dicha infamante señal. Estas industrias pueden rastrearse en varios pasajes de la obra de Quevedo ${ }^{26}$, pero El castigo de la miseria de María de Zayas muestra un retrato muy apropiado, en tanto que imita El casamiento engañoso:

[...] pensando hallar en la cama a su mujer, no halló sino un fantasma, o imagen de la muerte, porque la buena señora mostró las arrugas de la cara por entero, las cuales encubría con el afeite, que tal vez suele ser encubridor de años, que a la cuenta estaban más cerca de cincuenta y cinco que de treinta y seis, como había puesto en la carta de la dote, porque los cabellos eran pocos y blancos, por la nieve de los muchos inviernos pasados. Esta falta no era mucha, merced a los moños y a su autor, aunque en esta ocasión se la hizo a la pobre dama respecto de haberse caído sobre las almohadas, con el descuido del sueño, bien contra la voluntad de su dueño. Los dientes estaban esparcidos por la cama, porque, como dijo el príncipe de los poetas, daba perlas de barato, a cuya causa tenía don Marcos uno o dos entre los bigotes, demás que parecían tejado con escarcha, de lo que habían participado de la amistad que con el rostro de su mujer habían hecho (p. 277).

El engalanamiento con afeites como el solimán es muy usual en la figura de las meretrices $-\mathrm{y}$, curiosamente, también en la picaresca de protagonista femenino ${ }^{27}$ — como se ve en Rinconete y Cortadillo con la Gananciosa y la

24 El sentido de este parlamento se aclara poco más adelante, al final del mamotreto VI, p. 31, en el diálogo entre Lozana y una camisera sevillana, donde la pícara cuenta que una vieja la acusó públicamente de padecer el mal venéreo. Cito por la edición de Joset y Gernert.

25 Allaigre, 1985, p. 118.

26 Un Heráclito cristiano..., núms. 170, 199 y 201; Sueño del infierno, pp. 214-217; El mundo por de dentro, pp. 302-306; ver también Capitulaciones matrimoniales, en Prosa festiva completa, pp. 250-256, etc., etc.

27 Advierte con razón Brioso Santos, 1997, p. 130, n. 26: «Resulta, quizás, sintomático, observar que los pícaros, excepto las dos mujeres (Lozana y Justina) no sufren del chancro sifilítico, acaso porque sus contactos esporádicos con las mujerzuelas que los acogen entre sus mantas no son esenciales a la trama en muchos casos». 
Escalanta, quienes se acicalan y cubren con mantos para ejercer su profesión:

Al volver que volvió Monipodio, entraron con él dos mozas, afeitados los rostros, llenos de color los labios y de albayalde los pechos, cubiertas con medios mantos de anascote, llenas de desenfado y desvergüenza: señales claras por donde, en viéndolas Rinconete y Cortadillo, conocieron que eran de la casa llana, y no se engañaron en nada (p. 266).

Quevedo, en la Pregmática que han de guardar las hermanas comunes o Premáticas contra las cotorreras, dirigida a «las busconas, damas de alquiler, niñas comunes, sufridoras del trabajo, mujeres al trote, hembras mortales, recatonas del sexto, ninfas de daca y toma vinculadas en la lujuria», alude a su habilidad para curar las bubas venéreas:

Y demás desto, os mandamos que no seáis atrevidas las pecadoras chabacanas y badeas a vestir leonado, rosa seca, ni calzar media naranjada, traer monos de pata ni de revelación, y ellos airones de pedrería, ni alumbra[r] con vela, sino como cotorreras capuchinas vistáis remendado y durmáis en el suelo [y vos alumbréis con candil], pues por vuestras llagas y bubas entendéis más de mechas que de pabilos (en Prosa festiva completa, pp. 333-334; la cursiva es mía).

En efecto, para que las meretrices poseían remedios populares para curar la sífilis, al igual que métodos para evitar los embarazos ${ }^{28}$. Con mayor claridad se aprecian estas prácticas en La pícara Justina: la protagonista es posiblemente una prostituta falsamente arrepentida que decide salir de su tierra natal buscando medrar mediante un matrimonio ventajoso, como otras de sus congéneres. Para lograrlo, pretende aparentar una virtud de la que carece y trata de disimular los estragos que la enfermedad venérea ha causado en ella mediante el esmerado empleo de cosméticos. Ella confiesa «pagar culpas oscuras con penas claras» (Introducción, 1, p. 128), como las «alforzas o bregaduras» (Introducción, 2, p. 140) o arrugas faciales provocadas por el mal que disfraza con afeites varios. Sin olvidar que es «pelona», es decir, ha perdido el cabello debido a la «pelona francesa» que padece ${ }^{29}$. Para subsanar todo esto, recuerda en su vejez cómo se aderezaba:

tiempo hubo en el que relucía mi cara como bien acecalada; tiempo en el cual mi cara andaba al olio, mudando más figuras que juego de primera, ejercitando más metamorfosis que están escritos en el poeta de las Odas, mudando más colores que el camaleón, [...]; en fin, tiempo en el cual estaba

28 Dice Perry, 1993, p. 143: «Los remedios que utilizaban las prostitutas y cirujanos simplemente trataban los síntomas de la enfermedad y no podían prevenir el retorno después de un período en estado latente».

29 Ella lo explicita numerosas veces en la introducción. Empleo la edición de Torres. Sobre las pícaras como mujeres de mal vivir ver Cruz, 1989 (aunque con un enfoque muy marcado y discutible); Arredondo, 1993; Calzón García y Fernández Rodríguez, 2006; Zafra, 2009. 
en mi mano ser blanca o negra, morena o rubia, alegre o triste, hermosa o fea, diosa o sin días» (Introducción, 2, p. 141).

No en vano, «Peligra la fama de la mujer que se afeita» es refrán que recoge Correas, pues las mujeres podían ser consideradas in malam partem por tal práctica ya desde la Edad Media ${ }^{30}$. De hecho, los moralistas condenaban este quehacer como deshonesto; dice fray Antonio Marqués en Afeite y mundo mujeril (1617): «Las que [...] deseaban granjear nombre de honradas [...] habían de apartar de sí afeites y galas, por ser atavío de mujeres incestuosas, hábito de deslavadas y aderezo de rameras» (p. 234). La superficie pudorosa y decente, pues, podía encubrir una realidad muchas veces inesperada, como testifica metafóricamente Pietro Aretino en el Coloquio de las damas (1534): «muchas que conozco y conosces, que de quince años están hechas unas manzanas hermosas de fuera, blancas, rubias y coloradas, y de dentro no tiene tantas abejas una colmena cuantas ellas enfermedades encubiertas ${ }^{31}$. A su vez, Francisco Santos escribe muy significativamente en Día y noche de Madrid $(1663)^{32}$ :

\begin{abstract}
Iban estas dos aves noturnas con mucha color en el rostro, con que encubren o disfrazan la funda gálica; muchos dicen que la vergüenza arroja colores al rostro, y, según esto, ninguna de éstas tienen vergüenza, pues jamás se les ve color propio; que el que manifiestan después de compuestas es artificial (Discurso XIII, p. 756; mi cursiva).
\end{abstract}

No era tampoco la única enfermedad que invitaba al disimulo en la época: la viruela y otras afecciones dejaban igualmente desagradables señales en el rostro, que se intentaban encubrir por distintos medios, como los lunares postizos, por ejemplo; así, Brunel escribe: «se pintan tanto más para cubrir sus rostros variolosos que para embellecerse ${ }^{33}$. Y, cambiando de tercio, es también posible que, como ocurría en algunas de las manifestaciones de la enfermedad y en otras similares (léase la gonococia), la mujer contagiase al varón pero no resultase afectada: esta distinción puede ser el origen de la creencia de que el mal quedaba disimulado en la mujer, responsable también de su aparición debido a su concupiscencia, proverbial en la época ${ }^{34}$.

Esta opción - que podría apoyar la tesis de Márquez Villanueva- no redime a Estefanía, culpable de contagiar a Campuzano, a sabiendas o ignorándolo. Estefanía, ya tenga al principio o al final sentimientos amorosos

30 Ver Colón Calderón, 1995, pp. 66-67, 77; Frontón Simón, 1997.

31 Texto citado en Rey Hazas, 1983, p. 104. Señalo la fecha de composición del texto de Aretino, traducido en 1547 por Fernán Juárez.

32 Empleo la única edición moderna fiel a la princeps, según me consta.

33 Citado en García Mercadal, 1962, p. 269.

34 Jacquart y Tomasset, 1989, p. 189; Brioso Santos, 1997, p. 131. Erasmo, en el coloquio Conjugium impar (1524), expone las ideas del momento sobre la moralidad de las uniones con sifilíticos o entre ellos, junto con el daño que causan a la sociedad quienes insisten en transmitir el mal, siendo conscientes de ello (García-Verdugo, 1994, p. 102). 
respecto a Campuzano o carezca de ellos, en definitiva huye despojando a su marido de sus figuradas valiosas joyas. Y aunque las distintas variedades de la enfermedad «se confundían entre sí en el Renacimiento y se fundían inevitablemente con dolencias» afines como la lepra o la viruela ${ }^{35}$, dentro de la dinámica de la burla doble presentada en El casamiento engañoso, el mal padecido por Campuzano debe proceder necesariamente de Estefanía, quien no sólo le roba sus supuestamente ricas pertenencias, sino que le contagia una enfermedad asociada al contacto carnal. La propia estructura de la novela condiciona esta perspectiva. A mi juicio, la arriesgada perspectiva de Márquez Villanueva y otros pretende disminuir la culpabilidad de Estefanía en el matrimonio frustrado en el que tanto Campuzano como ella han salido engañados, cuando al robo y el fraude que perpetran ambos se suma el contagio del mal. Este es el golpe de gracia, el jaque mate que la cortesana depara a su rival en el tablero del matrimonio engañoso. El único refugio que ya le resta a la culpada es la cuestionable fiabilidad de Campuzano, juez y parte, cuya versión es la única que se ofrece en la novela. Faltaría, pues, el contraste con el relato de Estefanía que, por suerte o por desgracia, es imposible conocer, de modo que queda fuera de las fronteras del conocimiento para perderse en las brumas de la conjetura ${ }^{36}$. El tribunal de los lectores no puede dejarse engañar por la retórica y ha de considerar la economía narrativa del relato: tanto Campuzano como Estefanía son culpables de haber accedido a un casamiento engañoso desde sus inicios. Cada uno de ellos incurre en una serie de malas acciones y delitos, por lo que ninguno puede librarse de una justa condena, aunque cierto sector de la crítica insista en probar la absoluta culpabilidad de Campuzano en aras de favorecer a Estefanía. Especialmente osado se muestra Darnis ${ }^{37}$, quien afirma que Campuzano borra todas las pistas que pueden sugerir su culpabilidad. Nada más lejos de la realidad, como he intentado mostrar a la vez que probaba las malas artes de Estefanía.

\section{FINAL}

En conclusión y a pesar de las pruebas aportadas, puede afirmarse que a efectos del relato no importa demasiado si Estefanía posee o disfraza indicios sifilíticos. A todas luces, es una cortesana de honra aparente y deshonestidad encubierta que ha logrado sacar fruto (falso y reducido) de su engaño. Ya

35 Brioso Santos, 1997, p. 124, n. 6. Señala Orozco Acuaviva, 1998, p. 213, que en realidad las confusiones en textos literarios responden a descripciones de cuatro enfermedades distintas pero de un mismo origen biológico: el treponema humano, con formas atenuadas en América pero mortal en la Europa del siglo XVI.

36 García López, 2005, p. 48, piensa que ella «ha ocultado pocas cosas» en su relato «y ha sido más sincera» que el alférez. Sobre Campuzano como narrador infidente ver algunas notas en Sáez, 2010, pp. 217-220 y especialmente Sáez, 2011.

37 Darnis, 2007, p. 56. 
descubierta, huye con su galán sin pensárselo dos veces, acto clave que debe contribuir a la recta interpretación de la novela en su conjunto. Por ello, es sin duda culpable de haber engañado y contagiado a Campuzano, al igual que él es castigado por sus intenciones embaucadoras. Los dos personajes de corte (pseudo)picaresco acaban fracasando en sus aspiraciones y sufren condena por sus ardides. La ejemplaridad de este relato, por tanto, se encuentra en la reflexión sobre las apariencias y en el caso a evitar del matrimonio fundado en la ambición y el disimulo. Al final, Cervantes no sólo vincula la transmisión de la sífilis con las cortesanas, sino que irónicamente hace que los padecimientos causados por Estefanía — sin duda una «dama servida»— conduzcan a Campuzano a presenciar el prodigio narrado en el Coloquio de los perros, posible fruto de delirios o sueños durante su tratamiento o enfermedad ${ }^{38}$. El verdadero beneficio que obtiene Campuzano, y el lector de su mano, es la oportunidad de acercarse a la maravilla. Como confiesa a Peralta, «doy por bien empleadas todas mis desgracias por haber sido parte de haberme puesto en el hospital, donde vi lo que ahora diré, que es lo que ahora, ni nunca, vuesa merced podrá creer, ni habrá persona en el mundo que lo crea» (p. 643).

\section{BIBLIOGRAFÍA}

AlemÁn, Mateo, Guzmán de Alfarache I, ed. J. M. ${ }^{\mathrm{a}}$ Micó, 7. ${ }^{\mathrm{a}}$ ed., Madrid, Cátedra, 2006.

Allaigre, Claude (ed.), Francisco Delicado, Retrato de la Lozana Andaluza, Madrid, Cátedra, 1985.

Alonso CORTÉs, Narciso, «Los perros de Mahúdes», Revista de Filología Española, 26, 1942, pp. 298-302.

Alonso HernándeZ, José Luis, El lenguaje de los maleantes españoles de los siglos XVI y XVII: la germanía (Introducción al léxico del marginalismo), Salamanca, Universidad de Salamanca, 1979.

ArRedondo, María Soledad, «Pícaras. Mujeres de mal vivir en la narrativa del Siglo de Oro», Dicenda, 11, 1993, pp. 11-33.

AYlWARD, Edward T., «Significant Disparities in the Text of La tía fingida vis-à-vis Cervantes's El casamiento engañoso», Cervantes, 19.1, 1999, pp. 40-65.

Brioso SANTOS, Héctor, «El benéfico "mal francés" de Gaspar Lucas Hidalgo», en El sexo

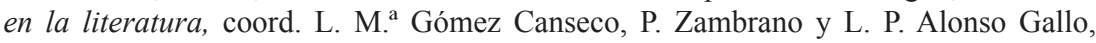
Huelva, Universidad de Huelva, 1997, pp. 123-132.

Bubnova, Tatiana, «Cervantes y Delicado», Nueva Revista de Filología Hispánica, 38.2, 1990, pp. 567-590.

CALzÓn GARCíA, José Antonio, y FernÁndez RodrígueZ, Natalia, «Entre la transgresión y la norma: pícaras y pecadoras penitentes en la narrativa española del Siglo de Oro», Archivum, 56, 2006, pp. 67-96.

CAnavaggio, Jean, «Aproximación al Proceso Ezpeleta», Cervantes, 17.1, 1997, pp. 25-45.

CANTIZANo PÉrez, Félix, «De las ninfas del Olimpo a las ninfas de las tasqueras: una visión de la prostitución en la España del Siglo de Oro», eHumanista, 15, 2010, pp. 154-177.

38 Ver Sáez, 2010, pp. 220-221; y otros apuntes en prensa. 
Cervantes, Miguel de, Entremeses, ed. A. Rey Hazas, Madrid, Alianza, 2006.

- (atribuida), La tía fingida, ed. F. Sevilla Arroyo, Burgos, Fundación Instituto Castellano y Leonés de la Lengua, 2005.

— Novelas ejemplares, ed. J. García López, Barcelona, Crítica, 2005.

COlÓn CALderón, Isabel, «De afeites, alcoholes y hollines», Dicenda, 13, 1995, pp. 65-82.

CORREAs, Gonzalo, Vocabulario de refranes y frases proverbiales, ed. digital R. Zafra Pamplona, Universidad de Navarra, 2000.

Cortés de TolosA, Juan, Lazarillo de Manzanares, ed. M. Zugasti, Barcelona, PPU, 1990.

Costa VIEIRA, Maria Augusta da, «El casamiento engañoso y las prácticas de representación», en Actas del XVI Congreso de la Asociación Internacional de Hispanistas. Nuevos caminos del Hispanismo... (París, 9-13 de julio, 2007), ed. P. Civil y F. Crémoux, Madrid/Frankfurt, Iberoamericana/Vervuert, 2010, s. p. (CD-Rom).

Covarrubias, Sebastián de, Tesoro de la lengua castellana o española, ed. integral e ilustrada I. Arellano y R. Zafra, Madrid/Frankfurt, Iberoamericana/Vervuert, 2006.

CruZ, Anne J., «Sexual Enclosure, Textual Escape: The Pícara as Prostitute in the Spanisf Female Picaresque Novel», en Seeking the woman in the Late Medieval and Renaissance Writings: Essays in feminist contextual criticism, Knoxville, University of Tennessee Press, 1989, pp. 135-159.

CRUZ DE AMENÁBAR, Isabel, «El traje barroco en el Virreinato del Perú 1650-1800: una metáfora del cuerpo», en Emblemata aurea. La emblemática en el arte y la literatura del Siglo de Oro, ed. R. Zafra y J. J. Azanza, Madrid, Akal, 2000, pp. 111-126.

DARNIS, Pierre, "Cervantes y el nacimiento del relato de enigma (I): el Casamiento engañoso en la historia literaria de Occidente», Voz y Letra, 18.1, 2007, pp. 49-66.

Deleito y PiÑUela, José, La mujer, la casa y la moda (en la España del rey poeta), 3. ${ }^{\text {a }}$ ed., Madrid, Espasa Calpe, 1966.

— La mala vida en la España de Felipe IV, 4. ${ }^{\text {a }}$ ed., Madrid, Espasa Calpe, 1967.

Delicado, Francisco, La lozana andaluza, ed. J. Joset y F. Gernert, Barcelona, Círculo de Lectores/Galaxia Gutenberg/Centro para la Edición de los Clásicos Españoles, 2007.

Delicado Puerto, G., Santas y meretrices. Herederas de la Magdalena en la literatura de los Siglos de Oro y la escena inglesa, Kassel, Reichenberger, 2011.

EgIDO, Aurora, El discreto encanto de Cervantes y el crisol de la prudencia, Vigo, Academia del Hispanismo, 2011.

El Saffar, Ruth A., Cervantes, «El casamiento engañoso» and «El coloquio de los perros», Londres, Grant and Culer/Tamesis Books, 1976.

Forcione, Alban K., Cervantes and the Mystery of Lawlessness. A Study of "El casamiento engañoso» $y$ "El coloquio de los perros», Princeton, Princeton University Press, 1984.

Fracastoro, Girolamo, Il contagio, le malattie contagiose e la loro cura, ed. y trad. V. Busacchi, Firenze, Leo S. Olschki, 1950.

FrONTÓN SimÓN, Isabel M., «Los afeites como artificio de la prostitución: imágenes eclesiásticas de la mujer medieval», Historia 16, 257, 1997, pp. 52-59.

García LóPeZ, Jorge (ed.), Miguel de Cervantes, Novelas ejemplares, Barcelona, Crítica, 2005.

García Mercadal, José (ed. y trad.), Viajes de extranjeros por España y Portugal, Valladolid, 1962, vol. 3.

GARCÍA-VERDUGO, María Luisa, "La Lozana andaluza» y la literatura del siglo XVI: la sifilis como enfermedad y metáfora, Madrid, Pliegos, 1994. 
GENTIL DA SiLva, José, «La mujer en España en la época mercantil: de la igualdad al aislamiento», en La mujer en la Historia de España (siglos XVI-XX). Actas de las segundas Jornadas de Investigación Interdisciplinaria sobre la Mujer, Madrid, Universidad Autónoma de Madrid, 1990, pp. 11-33.

Hsu, Carmen Y., Courtesans in the Literature of Spanish Golden Age, pról. F. Márquez Villanueva, Kassel, Reichenberger, 2002.

— «Estefanía de Caicedo y sus fuentes literarias», en Actas del XI Coloquio Internacional de la Asociación de Cervantistas (Seúl, 17-20 de noviembre de 2004), coord. Ch. Park, Seúl, Universidad Hankuk de Estudios Extranjeros, 2005, pp. 311-324.

Hutchinson, Steven, Economía ética en Cervantes, Alcalá de Henares, Centro de Estudios Cervantinos, 2001.

JaCQuart, Danielle, y Tomasset, Claude, Sexualidad y saber médico en la Edad Media, trad. J. L. Gil Arisu, Barcelona, Labor Universitaria, 1989.

LeÓn PINelo, Antonio, Velos en los rostros de las mujeres: sus consecuencias y sus daños, Santiago de Chile, Universidad de Chile, 1966, 2 vols.

LlORIS, Manuel, «El casamiento engañoso», Hispanófila, 39, 1970, pp. 15-20.

LÓPEZ DE ÚBEDA, Francisco, La pícara Justina, ed. L. Torres, Madrid, Castalia, 2010.

MARQUÉs, Antonio (O.S.A.), Afeite y mundo mujeril, ed. F. Rubio, Barcelona, Juan Flors, 1964.

MÁrquez Villanueva, Francisco, «Novela contra fábula: Campuzano, Estefanía y los perros de Mahúdes», en Cervantes en letra viva. Estudios sobre la vida y la obra, Barcelona, Reverso, 2005, pp. 268-285. [Antes en: Bulletin of Spanish Studies, 81.4, 2004, pp. 613-625.]

Martínez Gil, Fernando, Muerte y sociedad en la España de los Austrias, Cuenca, Universidad de Castilla-La Mancha, 2000.

Moreno Mengíbar, Andrés, y VÁzquez García, Francisco, «Poderes y prostitución en España (siglos XIV y XVII). El caso de Sevilla», Criticón, 69, 1997, pp. 33-49.

Orozco Acuaviva, Antonio, «La sífilis en Delicado y su Lozana Andaluza», Boletín de la Real Academia de Córdoba de Ciencias, Bellas Letras y Nobles Artes, 134, 1998, pp. 205-222.

PÉREZ IBÁÑEZ, María Jesús, «Galli vocant istum morbum morbum eius cuius est. Otra designación para el "mal francés"», Asclepio, 60.1, 2008, pp. 267-280.

PERIS, María del Carmen, «La prostitución valenciana en la segunda mitad del siglo XIV, n. ${ }^{\circ} 1 »$, Revista d'historia medieval, 1, 1990, pp. 179-199.

PERRY, Mary Elizabeth, "Ni espada rota ni mujer que trota», Mujer y desorden social en la Sevilla del Siglo de Oro, trad. M. Fortuny Minguella, Barcelona, Crítica, 1993.

Plauto, Tito Maccio, Comedias I, ed. y trad. J. Román Bravo, 8. ${ }^{\mathrm{a}}$ ed., Madrid, Cátedra, 2007.

PONCE CÁRDENAS, Jesús, «De burlas y enfermedades barrocas: la sífilis en la obra poética de Pantaleón de Ribera y Miguel Colodrero de Villalobos», Criticón, 100, 2007, pp. 115-142.

PRATS Y BOSCH, Antonio, La prostitución y la sifilis: ensayo acerca de las causas de la propagación de las enfermedades sifiliticas y los medios de oponerse a ella, Barcelona, Librería de El Plus Ultra, 1861.

Profeti, Maria Grazia, «Mujer-libre, mujer-perdida: una nueva imagen de la prostituta a fines del siglo XVI y principios del XVII», en Images de la femme en Espagne aux $X V I^{e}$ et $X V I I^{e}$ siècles. Des traditions aux renouvellements et à l'èmergence d'images nouvelles. Colloque International (Sorbonne et Collège d'Espagne, 28-30 septembre 1992), dir. A. Redondo, Paris, Presses de la Sorbonne Nouvelle, 1994, pp. 195-205. 
Quevedo, Francisco de, Historia de la vida del buscón, ed. I. Arellano, 30. a ed., Madrid, Austral, 2007.

- Los sueños, ed. I. Arellano, 5. a ed., Madrid, Espasa Calpe, 2007.

- Prosa festiva completa, ed. C. C. García Valdés, 2. ${ }^{a}$ ed., Madrid, Cátedra, 2007.

- Un Heráclito cristiano, Canta sola a Lisi y otros poemas, ed. I. Arellano y L. Schwartz, Barcelona, Crítica, 1998.

ReY HAZAS, Antonio, «La compleja faz de una pícara: hacia una interpretación de $L a$ pícara Justina», Revista de Literatura, 45, 1983, pp. 87-109.

RodRíGueZ-Luis, Julio, Novedad y ejemplo de las «Novelas» de Cervantes, Madrid, Porrúa Turranzas, 1980, 2 vols.

SÁEZ, Adrián J., «Estrategias de la verosimilitud en el Coloquio de los perros», en Crítica, ecdótica y poética del «Quijote», ed. J. G. Maestro y E. Urbina, Anuario de Estudios Cervantinos, 6, 2010, pp. 215-228.

- «Acerca del narrador infidente cervantino: El casamiento engañoso y el Coloquio de los perros», en Entre lo sensible y lo inteligible: Música, poética y pictórica en la literatura cervantina, ed. J. G. Maestro y E. Urbina, Anuario de Estudios Cervantinos, 7, 2011, pp. 189-209.

— «El "divino don de la habla": el Coloquio de los perros desde la tradición clásica y bíblica (contribución al estudio de sus fuentes)», en Visiones y revisiones cervantinas. Actas selectas del VII Congreso Internacional de la Asociación de Cervantistas (Münster, 30 de septiembre-4 de octubre de 2009), ed C. Strosetzki, en prensa.

Salas Barbadillo, Alonso Jerónimo de, La hija de Celestina, ed. E. García Santo-Tomás, Madrid, Cátedra, 2008.

Santos, Francisco, Día y noche de Madrid, ed. E. Suárez Figaredo, Lemir, 14, 2010, pp. 629-796.

SuÁrez de FigueroA, Cristóbal, Plaza universal de todas ciencias y artes, ed. M. Jalón, Valladolid, Junta de Castilla y León, 2006, 2 vols.

TEMPRANO, Emilio, Vidas poco ejemplares: viaje al mundo de las rameras, los rufianes y las celestinas (siglos XVI-XVIII), Madrid, Ediciones del Prado, 1995.

VÉLez De GuevarA, Luis, El diablo Cojuelo, ed. E. Rodríguez Cepeda, Madrid, Cátedra, 1988 .

VILANOVA, Antonio, «Cervantes y la Lozana andaluza», Ínsula, 77, 1952, p. 5.

ZAFrA, Enriqueta, Prostituidas por el texto: discurso prostibulario en la picaresca femenina, West Lafayette, Purdue University Press, 2009.

ZAYAS y SOTOMAYOR, María de, Novelas amorosas y ejemplares, ed. J. Olivares, Madrid, Cátedra, 2000.

Recibido: 20 de septiembre de 2010

Aceptado: 1 de abril de 2011 


\title{
Resumen
}

Se analiza la figura de doña Estefanía de Caicedo, mujer con la que se casa Campuzano, justificando su condición licenciosa por su actitud y ardides (tapada, afeites, etc.), a la par que se estudia su relación con la sífilis, enfermedad que transmite al alférez dentro del esquema del engaño mutuo presentado en esta novela cervantina.

Palabras clave: El casamiento engañoso, doña Estefanía de Caicedo, cortesana / «dama servida», engaño mutuo, sífilis.

Title: «Pata es la traviesa»: the courtesan Estefanía, the mutual deceive and the syphilis in The deceitful marriage

\begin{abstract}
This article analizes the figure of doña Estefanía de Caicedo, woman who Campuzano gets married, justifying her immoral behaviour for her attitude and tricks («tapada», cosmetics, etc.). Furthermore, it is also studied her relation with syphilis, illness she passes on to the second lieutenant inside the scheme of mutual deceive presented in this cervantine novel.
\end{abstract}

Key words: El casamiento engañoso, doña Estefanía de Caicedo, courtesan / «dama servida», mutual deceive, syphilis. 